\title{
RESEARCH
}

Open Access

\section{USP16 regulates castration-resistant prostate cancer cell proliferation by deubiquitinating and stablizing c-Myc}

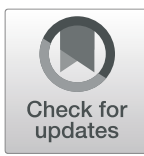

Jianchao Ge ${ }^{\dagger}$, Wandong Yư ${ }^{\dagger}$, Junhong Li, Hangbin Ma, Pengyu Wang, Yinghao Zhou, Yang Wang, Jun Zhang ${ }^{*}$ and Guowei Shi

\begin{abstract}
Background: c-Myc, a well-established oncogene, plays an important role in the initiation and progression of various cancers, including prostate cancer. However, its mechanism in cancer cell remains largely unknown and whether there exist a deubiquitinase targeting c-Myc also remains elusive.
\end{abstract}

Methods: Bioinformatic analysis and shRNA screening methods were used to identify potential deubiquitinases that correlate with c-Myc gene signature. Cell proliferation and viability were measured by Cell-Counting-Kit 8 and colony formation assays. A mouse xenograft model of PC3 cells was established to confirm the function of USP16 in vivo. The interaction between USP16 and c-Myc protein was assessed by co-immunoprecipitation and protein co-localization assays. Immunohistochemistry staining was performed to detect the expression of USP16, Ki67, and c-Myc in xenograft tissues and clinical tumour tissues. Furthermore, the correlation between USP16 and c-Myc was confirmed by RNA sequencing.

Results: Functional analyses identified USP16, known as a deubiquitinase, was strongly correlated with the c-Myc gene signature. Depletion of USP16 was shown to significantly suppress the growth of PCa cells both in vitro and in vivo. Co-immunoprecipitation and ubiquitination assays confirmed that USP16 served as a novel deubiquitinase of c-Myc and overexpression of c-Myc significantly rescued the effects of USP16 disruption. Immunohistochemistry staining and RNA-seq tactics were further used to confirm the positive correlation between USP16 and c-Myc expression. Expression of USP16 in human PCa tissues was higher than that seen in normal prostate tissues and its high expression was found associated with poor prognosis.

Conclusions: USP16 serves as a novel deubiquitinase of c-Myc. Downregulation of USP16 markedly suppressed PCa cell growth both in vitro and in vivo. USP16 regulates PCa cell proliferation by deubiquitinating and stabilizing cMyc, making it a potential therapeutic candidate for the treatment of PCa.

Keywords: USP16, C-Myc, Deubiquitinase, Prostate cancer

\footnotetext{
*Correspondence: urojason1984@163.com; dr.sgw@189.cn

†Jianchao Ge and Wandong Yu contributed equally to this work.

Department of Urology, The Fifth People's Hospital of Shanghai, Fudan

University, No. 801, Heging Road,Minhang District, Shanghai 200240, People's

Republic of China
}

(c) The Author(s). 2021 Open Access This article is licensed under a Creative Commons Attribution 4.0 International License, which permits use, sharing, adaptation, distribution and reproduction in any medium or format, as long as you give appropriate credit to the original author(s) and the source, provide a link to the Creative Commons licence, and indicate if changes were made. The images or other third party material in this article are included in the article's Creative Commons licence, unless indicated otherwise in a credit line to the material. If material is not included in the article's Creative Commons licence and your intended use is not permitted by statutory regulation or exceeds the permitted use, you will need to obtain permission directly from the copyright holder. To view a copy of this licence, visit http://creativecommons.org/licenses/by/4.0/. The Creative Commons Public Domain Dedication waiver (http://creativecommons.org/publicdomain/zero/1.0/) applies to the data made available in this article, unless otherwise stated in a credit line to the data. 


\section{Background}

Prostate cancer $(\mathrm{PCa})$ is one of the leading causes of death in men worldwide [1]. Due to the significance of androgen receptor (AR) signalling in tumourigenesis of $\mathrm{PCa}$ [2], most patients with primary $\mathrm{PCa}$ receive androgen deprivation treatment (ADT) as their first-line therapy [3]. Although ADT could achieve strong response at the early stage of $\mathrm{PCa}$ treatment, almost all the patients relapse into castration-resistant prostate cancer (CRPC), which is considered as the latest stage of $\mathrm{PCa}$ and almost incurable, within 18-24 months [4]. As a result, patients with CRPC were forced to endure chemotherapy, such as docetaxel [5], which would cause severe side effects and deteriorate their quality of life. Hence, novel therapeutic strategies are in an urgent need for $\mathrm{PCa}$, especially CRPC treatment.

The protein product of pro-oncogene $M Y C$ is a potent transcription factor that regulates the transcription of at least $15 \%$ of the entire genome [6], governs a diverse array of biological processes including cell proliferation [7], metabolism [8], protein translation [9], and cellcycle progression [10]. Moreover, $M Y C$ has also been found as one of the key drivers of CRPC and neuroendocrine prostate cancer (NEPC) pathogenesis [11]. c-Myc is frequently overexpressed in CRPC and its expression is correlated with poor outcomes [12], while N-Myc drives NEPC progression from human prostate epithelium [13]. It has been reported that reduction of $M Y C$ levels in mice benefits multiple organs and promotes longevity [14].

Ubiquitination is a tightly regulated post-translational modification that could influence a wide range of physiological and pathological processes [15]. Deubiquitinases (DUBs) can reverse ubiquitination process by removing ubiquitin molecule from target proteins [16]. $M Y C$ is a short-lived protein and its stability is precisely regulated by the ubiquitin-proteasome system [17]. Several DUBs are known to regulate $M Y C$ stabilization including USP7 [18], USP22 [19], USP28 [20], USP36 [21], and USP37 [22]. Furthermore, P22077, a small molecule inhibitor of USP7, was reported to highly suppress growth of N-Myc-amplified neuroblastoma in a xenograft model [18]. Hence, selectively inhibiting DUBs that stabilize $M Y C$ could be an attractive strategy for the treatment of $M Y C$-driven cancers.

Here, we performed a genome-wide screen to identify DUBs that are positively correlated with the c-Myc gene signature in PCa. As a result, USP16 was selected and revealed as a potential regulator of PCa cell proliferation both in vitro and in vivo. Moreover, USP16 was observed to co-localize and interact with c-Myc. In addition, knockdown of USP16 significantly reduced cMyc abundance at the post-translational level, while overexpression of wild-type USP16, instead of its catalytic-inactive mutant (C205S) [23], stabilized c-Myc. Together, these data confirmed the role of USP16 as a novel c-Myc deubiquitinase, making it a potential therapeutic candidate for the treatment of primary $\mathrm{PCa}$ and CRPC.

\section{Methods \\ Cell culture}

PC3 and DU145 cell lines were obtained from the American Type Culture Collection (Manassas, VA). PC3 cells were cultured in RPMI1640 medium and DU145 cells were cultured in Dulbecco's Modified Eagle's medium (DMEM) supplemented with 10\% foetal bovine serum (Gemini, Woodland Hills, CA) and 1\% penicillin/ streptomycin (Gibco, Grand Island, NY). All cells were maintained at $37^{\circ} \mathrm{C}$ in a $5 \% \mathrm{CO} 2$ humidified incubator.

\section{Plasmids and transfection}

Short hairpin RNA (shRNA) sequences are listed in Additional file 1: Table S1. These sequences were cloned into the pLKO.1 vector, while Flag-tagged USP16 and cMyc were cloned into the pLVX vector (Clontech 632, 187). Plasmids were transfected into HEK293FT cells using PEI $25 \mathrm{~K}$ (23966-1; Polysciences, Warrington, PA, USA) according to the manufacturer's instructions. Stable transformants of PC3 and DU145 cells were isolated in standard medium supplemented with puromycin $(5 \mu \mathrm{g} / \mathrm{mL})$ (Sigma-Aldrich, St. Louis, MO, USA) for 7 days.

The siRNAs were chemically synthesized by Genepharma (Shanghai, China). The sequences of siRNA ( $5^{\prime}$ $3^{\prime}$ ) are as follows: siNC (UUCUCCGAACGUGUCA CGU), siUSP16 (CCGGAAAUCUUAGAUUUGGCUC CUU). Cells were transfected with Lipofectamine 2000 (Invitrogen, Carlsbad, CA) following the manufacturer's instructions and the culture medium was replaced about $6 \mathrm{~h}$ later. Forty-eight h after transfection, the cells were used for further experiments.Cell proliferation and colony formation assay.

Cell growth was measured by Cell Counting Kit-8 (CK04; Dojindo, Kumamoto, Japan) at indicated time points following the manufacturer's instructions. The cells were seeded in 96-well plates (1000 cells per well). Ten $\mu \mathrm{L}$ CCK8 reagent was added to $100 \mu \mathrm{L}$ medium in each well and then incubated at $37^{\circ} \mathrm{C}$ for $3 \mathrm{~h}$. The absorbance values were detected using a microplate reader (Tecan, Mechelen, Belgium) at $450 \mathrm{~nm}$ (A450).

Cells were cultured in 6-well plates (2000-3000 cells per well) in complete medium for 10-14 days depending on colony size. The cells were then fixed with methanol for $20 \mathrm{~min}$ and stained with $0.5 \%$ crystal violet for $1 \mathrm{~h}$, and images were captured following a twice wash of PBS. 


\section{Reagents and primary antibodies}

MG132(52801ES08) and CHX (40325ES03) were purchased from Yeason (Shanghai, China). The following antibodies were used for western blotting: USP16 (A5861; Abclonal), c-Myc (GTX103436; GeneTex), $\beta$ actin (sc-47,778; Santa Cruz Biotechnology). Antibodies used for immunohistochemistry: USP16 (HPA021140; Sigma-Aldrich), Ki67 (sc-15,402; Santa Cruz), c-Myc (\#ab32072, Abcam). Antibodies used for immunoprecipitation and immunofluorescence: Flag (\#30503ES60, Yeason), USP16 (HPA021140; Sigma-Aldrich), c-Myc (13987S, Cell Signaling Technology).

\section{Immunoprecipitation and immunoblotting}

Extracts for immunoprecipitation were prepared using NP-40 lysis buffer containing phenylmethylsulphonyl fluoride. The extracts were then incubated with protein A/G beads supplemented with the indicated antibodies at $4{ }^{\circ} \mathrm{C}$ overnight on a rotator. After incubation, beads were washed for three times and boiled in $1 \times$ loading buffer. Protein samples were loaded and separated by SDS-PAGE, and then the proteins were transferred to PVDF membranes and incubated with primary antibodies. Membranes were washed with $1 \times$ TBST and incubated with anti-mouse or anti-rabbit secondary antibodies for $1 \mathrm{~h}$. Densitometric analysis was conducted using NIH ImageJ software.

\section{Real-time PCR analysis}

RNA was isolated using TRIzol reagent (Invitrogen, Carlsbad, CA, USA) according to the manufacturer's instructions. RNA was then reverse transcribed into cDNA using a PrimeScript 1st Strand cDNA Synthesis Kit (6110A; TaKaRa, Kyoto, Japan). qRT-PCR was performed using TB Green Premix ExTaq (Tli RNaseH Plus) (RR420; TaKaRa) on an ABI7500 System (Applied Bio Systems, Foster City, CA, USA). The relative expression levels of genes were calculated using the $2-\Delta \Delta \mathrm{Ct}$ method. GAPDH was used as an internal control for qRT-PCR. The sequence of primers used to amplify the target genes are listed in Additional file 1: Table S1.

\section{Animal experiments}

Approximately $1 \times 10^{6}$ PC3 cells infected by a lentivirus were mixed with Matrigel (volume, 1:1; 356,234; Corning, NY) and subcutaneously implanted into sixweek-old male nude mice $(n=9)$. All mice were sacrificed after 8 weeks, at which point the tumours were dissected and weighed. The xenografts were paraffinembedded for haematoxylin-eosin and immunohistochemical staining. The protocol was approved by the Institutional Animal Care and Use Committee of Shanghai Veterinary Research Institute.

\section{IHC staining}

Tissue sections were deparaffinised in xylene solutions followed by rehydration in graded ethanol. After this, slides were incubated in 3\% hydrogen peroxide for 10 min and then boiled in citrate solution $(\mathrm{pH}=6)$ in a microwave for $20 \mathrm{~min}$ and cooled to room temperature. The slides were then blocked in an appropriate blocking solution for $30 \mathrm{~min}$ and subsequently incubated with primary antibodies overnight at $4{ }^{\circ} \mathrm{C}$. The final IHC scores $=$ intensity score $\times$ percentage score. Intensity was scored according to staining intensity ( 0 : negative, 1 : weak, 2: moderate, and 3: strong); percentage score was evaluated based on the percentage of stained cells (0: 0\%, 1: $1-25 \%$, 2: $26-50 \%, 3: 51-75 \%$, and 4: 76-100\%).

\section{Immunofluorescence}

Cells were seeded at a density of $2 \times 10^{4}$ cells/well in a 24-well plate and cultured for $24 \mathrm{~h}$. After this, the cells were fixed with paraformaldehyde, permeabilized with $0.1 \%$ Triton $\mathrm{X}-100$ for $10 \mathrm{~min}$, incubated with the primary antibodies at $4{ }^{\circ} \mathrm{C}$ overnight, and then incubated with fluorescent-labelled secondary antibodies for $1 \mathrm{~h}$. The nuclei were counterstained with DAPI. Cell images were captured with a fluorescence microscope (Nikon Eclipse E200).

\section{RNA sequencing and expression analysis}

Total RNA extracted from indicated groups of PC3 cells was subjected to RNA sequencing (RNA-seq) performed by Majorbio Biopharm Technology (Shanghai, China). Expression profiles were obtained using the Majorbio Cloud Platform. The sequence data have been uploaded to Gene Expression Omnibus (GEO, GSE160818).

Gene expression datasets of human PCa samples were downloaded from NCBI-GEO (https://www.ncbi.nlm. nih.gov/geo/). Gene set enrichment analysis (GSEA) was performed using software provided by the Broad Institute (http://www.broadinstitute.org/gsea/index.jsp). The permutation type was "phenotype", and the genes were ranked based on Pearson correlation score.

\section{Statistical analysis}

All statistical analyses were performed using GraphPad Prism software (version 7; GraphPad Software, La Jolla, CA). Quantitative data obtained from experiments with biological replicates are presented as mean \pm SD. Pearson correlation and linear regression analysis were performed. Tumor onset analysis was performed with logrank tests. Two-tailed Student's t-test was used to analyze the quantitative data and $p$ values $<0.05$ were considered statistically significant. " $p<0.05, " * * 0<01$ and ${ }^{* * *} p<0.001$. 
a

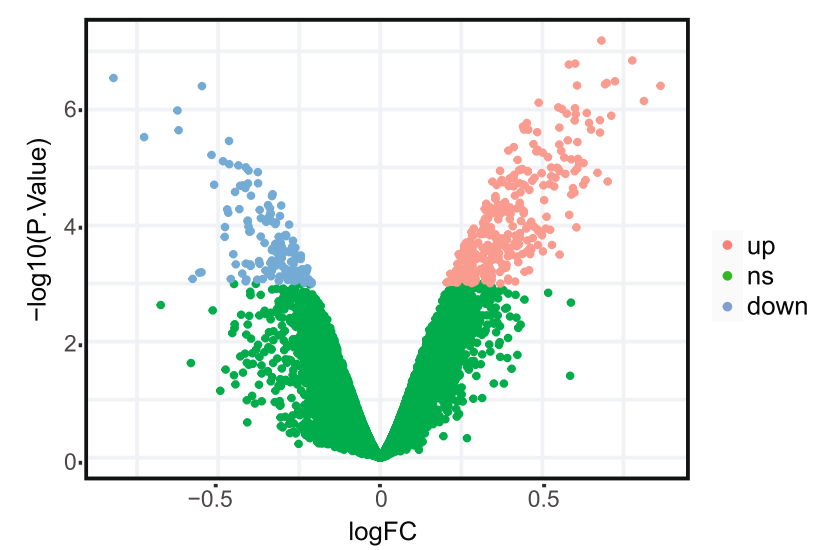

C

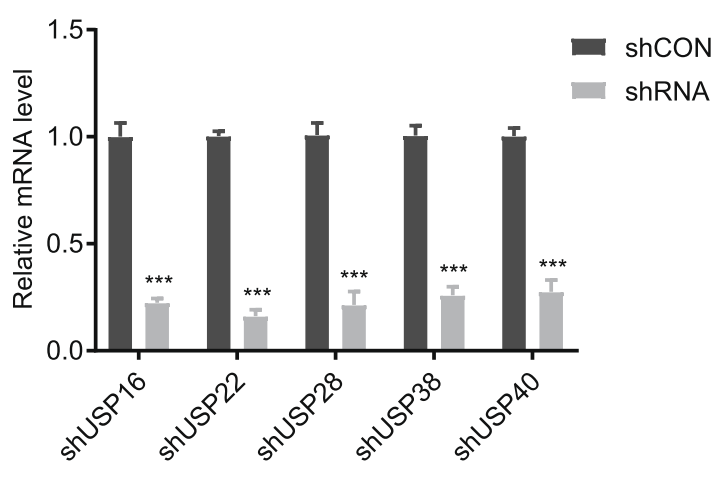

e
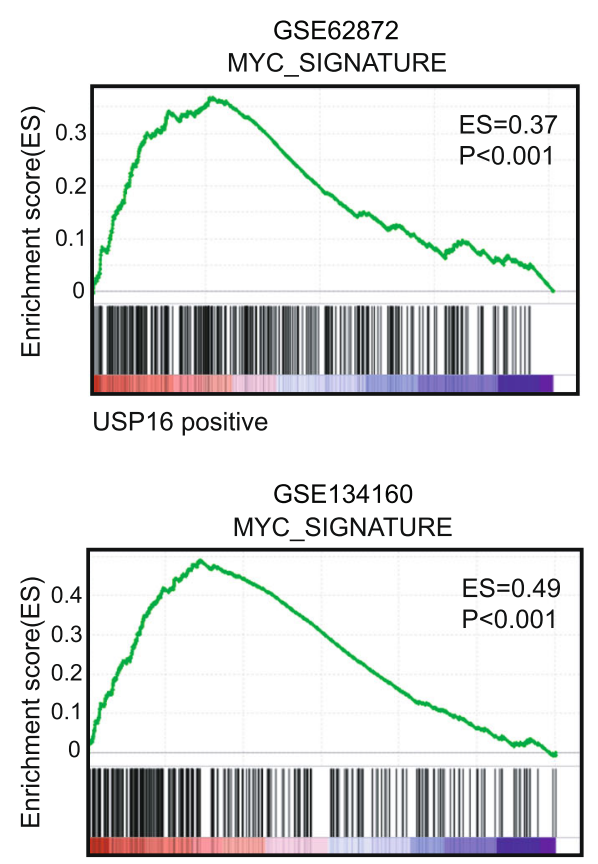

USP16 positive b

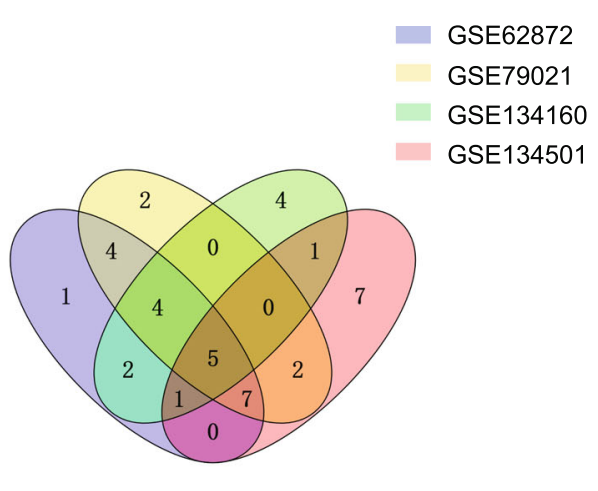

d

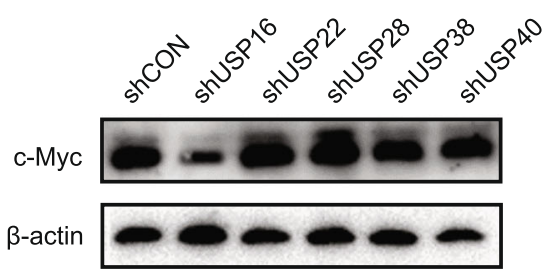

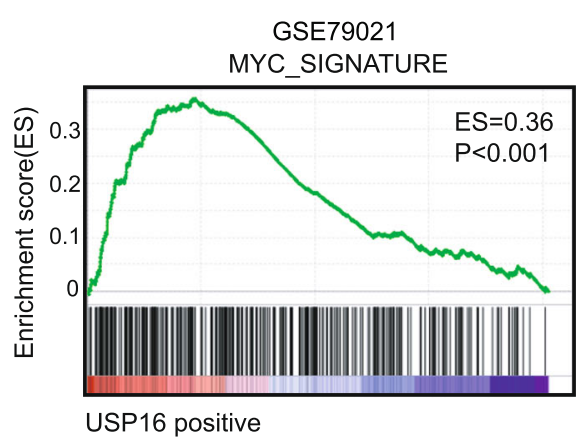

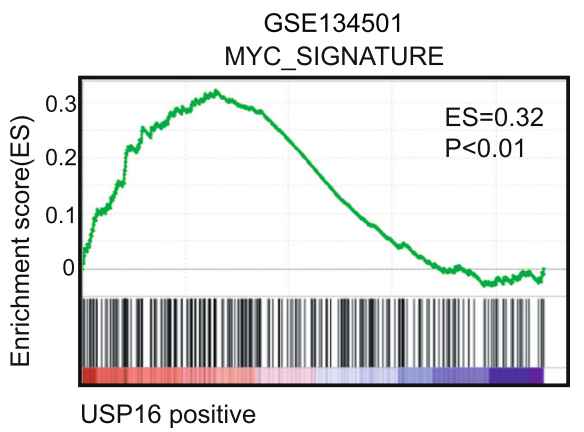

Fig. 1 (See legend on next page.) 
(See figure on previous page.)

Fig. 1 USP16 is highly associated with c-Myc gene signature. a A volcano plot presents the differentially expressed genes between control and cMyc-overexpressing PCa cells. $\mathbf{b}$ Venn diagram showing USPs that were positively correlated with the c-Myc gene signature in PCa datasets. USP numbers are labelled inside each of the ovals. $\mathbf{c}$ Knockdown efficiency of shRNAs is shown. $\mathbf{d}$ Western blot analysis of PC3 cells transfected with indicated shRNAs. e Plots indicating a significant positive correlation between USP16 and the c-Myc gene signature in four independent PCa datasets

\section{Results}

USP16 is positively correlated with the c-Myc gene signature

To explore potential DUBs that may regulate c-Myc signalling, we performed differential expression analysis of control and c-Myc-overexpressing $\mathrm{PCa}$ cells (GSE51384), revealing 310 c-Myc mediated up-regulated genes (Fig. 1a and Additional file 2: Table S2). This set of genes was defined as a c-Myc gene signature and then imported into GSEA software for gene set enrichment analysis. Using this dataset, we screened for ubiquitinspecific proteases (USP) that were positively correlated with the c-Myc signature in four publicly available human PCa datasets (GSE62872, GSE79021, GSE134501, and GSE134160). Merging of these four independent analyses revealed a set of five USPs (USP16, USP22, USP28, USP38, and USP40) that consistently were identified across all dataset analyses (Fig. 1b).

Next, we transfected shRNAs of the five USPs into PC3 cells, and the knockdown efficiency of shRNAs was measured by qRT-PCR (Fig. 1c). Analysis of c-Myc protein levels by Western blot revealed that knockdown of USP16 significantly decreased the abundance of c-Myc (Fig. 1d). Taken together, these data suggest that USP16 is strongly associated with the c-Myc signalling pathway and may play an important role in $\mathrm{PCa}$. The positive correlation between USP16 and the c-Myc gene signature in PCa datasets was shown in Fig. 1e.

\section{Targeting USP16 inhibits CRPC cells proliferation in vitro} To better understand the role of USP16 in PCa cells in vitro, we silenced USP16 in two CRPC cell lines: PC3 and DU145 cells, which characterized by androgenindependent growth. The knockdown efficiency of USP16 was confirmed by Western blot (Fig. 2a). Cells proliferation were then analysed using a CCK-8 assay, and the results revealed that knockdown of USP16 markedly reduced cell growth in PCa cells (Fig. 2b and c). Colony formation assays yielded the similar results that USP16 deletion results in significant reductions in cell colony numbers relative to controls (Fig. $2 \mathrm{~d}$ and e). Concordantly, we found that ectopic expression of USP16 mostly restored the proliferation rate of USP16 knockdown cells (Fig. $2 \mathrm{f}$ and g). Collectively, these results indicate that USP16 is necessary for the growth of CRPC cells.

\section{USP16 knockdown suppresses growth of PCa tumour xenografts}

To further elucidate the role of USP16 in the growth of PCa cells in vivo, PC3 cells stably expressing shRNA targeting USP16 (shUSP16) or vector control (shCON) were subcutaneously injected into 6-week-old male nude mice. After 8 weeks, the mice were sacrificed and the xenografts were extracted for further investigation. The control group xenografts (shCON) were larger and weighed significantly heavier than those in the USP16 knockdown group (shUSP16) (Fig. 3a and b). In addition, the inhibition of USP16 led to a delayed tumour onset in nude mice (Fig. 3c). IHC staining analysis of the xenograft tissues revealed that inhibiting USP16 reduced Ki67 expression, indicating USP16 knockdown impaired the proliferation of PCa cells (Fig. $3 \mathrm{~d}-\mathrm{f}$ ). These results demonstrate that inhibiting USP16 significantly suppressed PCa cell growth in vivo.

\section{USP16 stabilizes c-Myc in a deubiquitination activity- dependent manner}

In previous assays, we observed the malignant effects of USP16 in PCa cells, and then we would like to further uncover the underlying mechanisms of how USP16 exert such effects. We found that knockdown of USP16 dramatically reduced c-Myc protein abundance but did not affect its mRNA levels (Fig. 4a and b), suggesting that the regulation of $\mathrm{c}-\mathrm{Myc}$ by USP16 occurs at the posttranscriptional level. Moreover, treatment with proteasome inhibitor MG132 significantly attenuated the effect of USP16 knockdown on c-Myc protein level (Fig. 4c and d). Next, we examined whether USP16 could regulate the stability of $\mathrm{c}-\mathrm{Myc}$ using a cycloheximide (CHX) chase assay. PC3 cells were treated with $50 \mu \mathrm{g} / \mathrm{L}$ $\mathrm{CHX}$ and c-Myc protein levels were measured at a series of indicated time points. We found that ectopic expression of USP16 enhanced the stability of c-Myc protein, while USP16 knockdown reduced the half-life of c-Myc protein (Fig. 4e and f). These data indicate that USP16 specifically sustains c-Myc stability through the ubiquitination-proteasome pathway.

\section{USP16 deubiquitinates c-Myc}

To explore the functional links between USP16 and cMyc, we transfected Flag-tagged and V5-tagged plasmids into HEK293T cells, followed by immunoprecipitation 


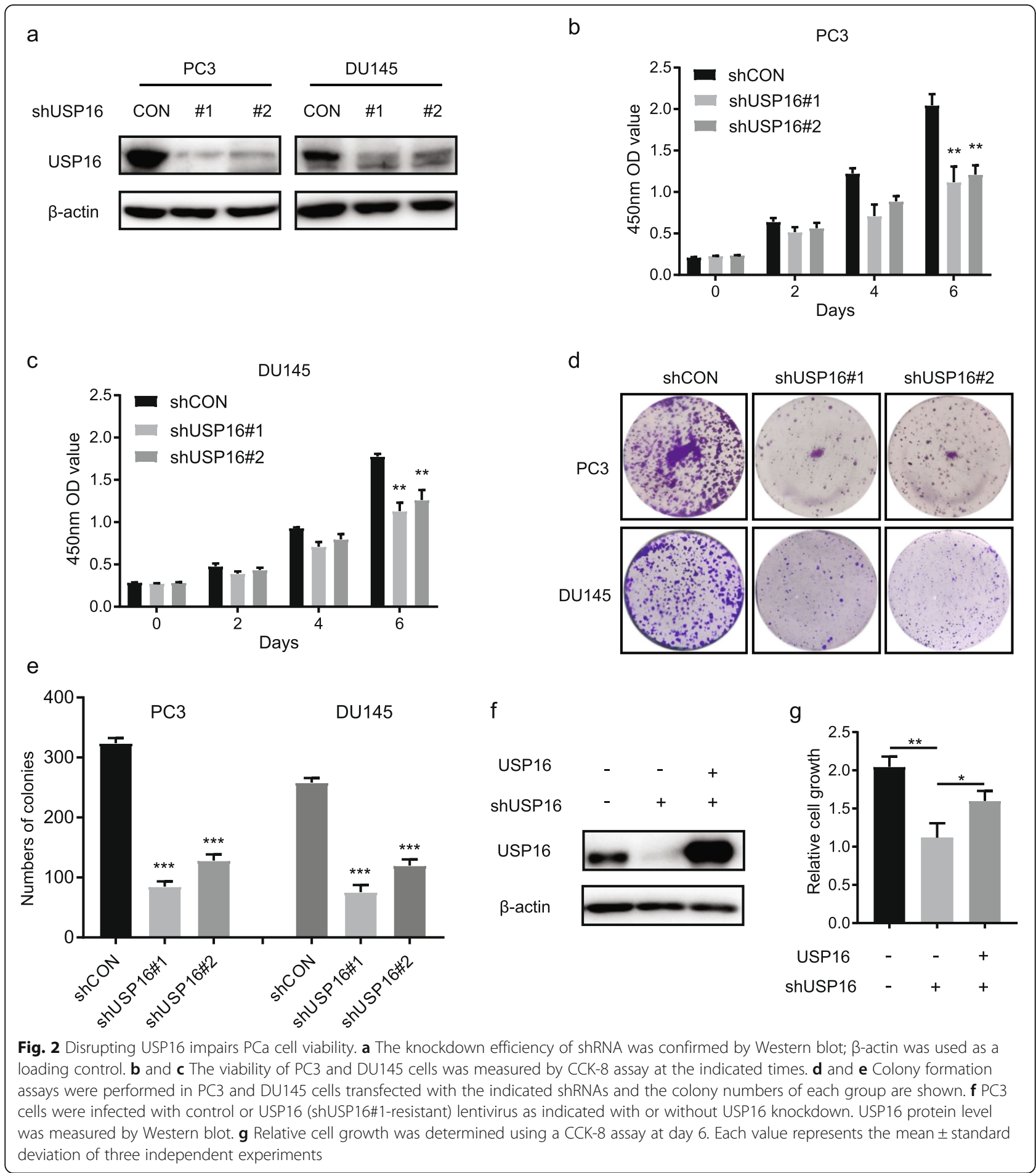

with an anti-Flag antibody. Ectopically expressed USP16 was found to significantly interact with $\mathrm{c}-\mathrm{Myc}$ and vice versa (Fig. 5a and b). Furthermore, USP16 protein was detected when Flag-c-Myc was immunoprecipitated by Flag antibody, and inversely c-Myc was detected when Flag-USP16 was immunoprecipitated in PC3 cells (Fig. $5 \mathrm{c}$ and $\mathrm{d}$ ). The interaction between endogenous $\mathrm{c}-\mathrm{Myc}$ and USP16 was also demonstrated in PC3 cells (Fig. 5e). Next, we confirmed the co-localization of USP16 and cMyc in PC3 and DU145 cells using immunofluorescent staining (Fig. 5f). Together, these data indicate that USP16 both interacts and co-localizes with c-Myc.

To identify whether USP16 serves as a DUB of c-Myc, HEK293T cells were transfected with plasmids encoding 


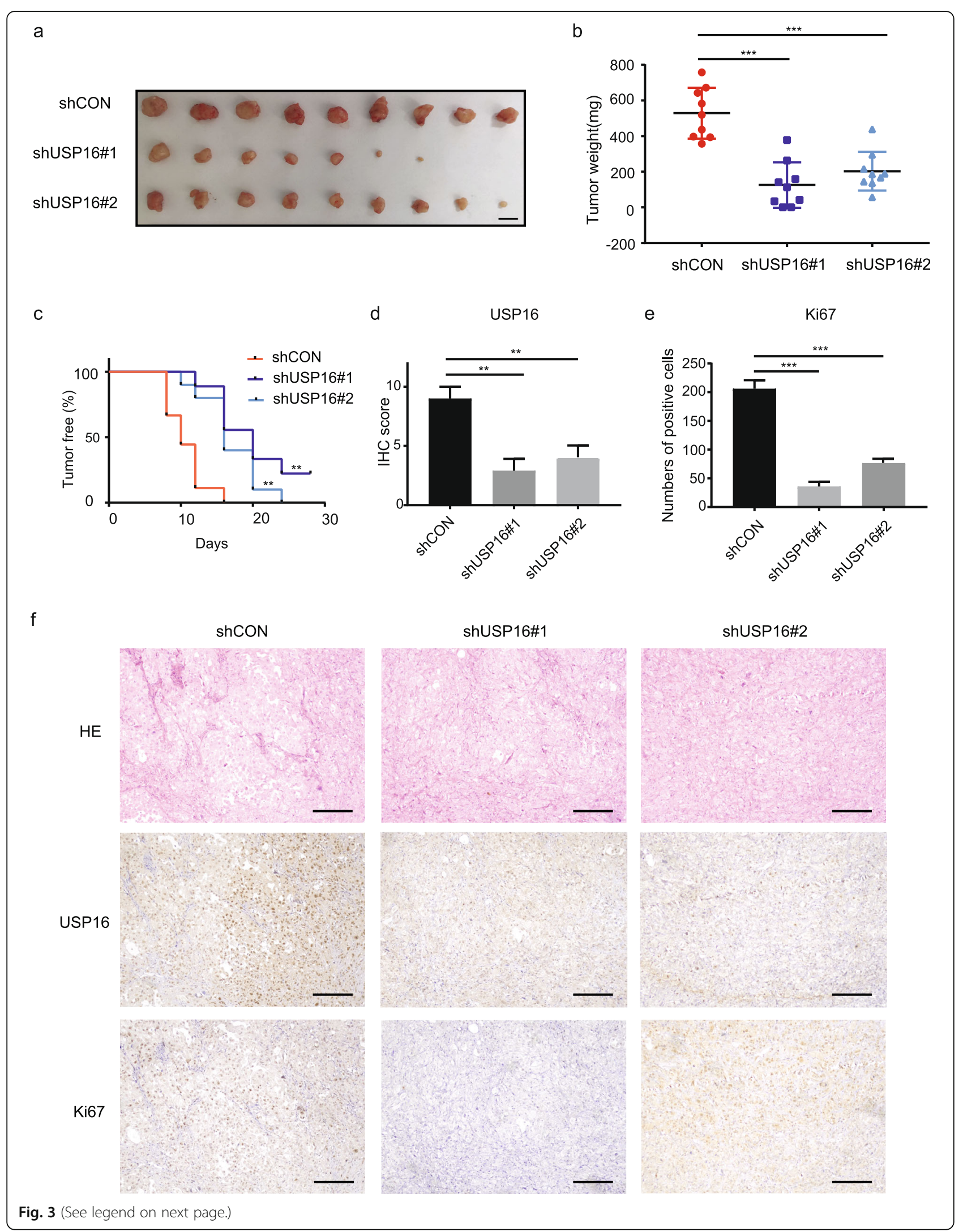


(See figure on previous page.)

Fig. 3 Knockdown of USP16 impeded PCa tumour growth in vivo. a PC3-shCON and PC3-shUSP16 cells $\left(5 \times 10^{5}\right)$ were suspended in Matrigel (volume, 1:1) and subcutaneously implanted into nude mice $(n=9)$. Mice were sacrificed 8 weeks later, and the volumes of the xenograft tumours were determined (scale bar: $10 \mathrm{~mm}$ ). b The weights of the xenograft tumours are shown. Error bars represent mean \pm standard deviation (MannWhitney test; $n=9$ ). c Kaplan-Meier analysis of tumour onset (log rank). $\mathbf{d}$ USP16 expression is shown as an IHC score (Mann-Whitney test). e Ki67 expression is expressed as the number of positive cells. $\mathbf{f}$ Haematoxylin-eosin (HE) staining and USP16 and Ki67 IHC staining in tumour xenografts (scale bar: $100 \mu \mathrm{m}$ )

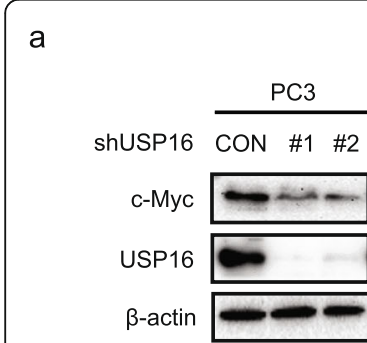

b

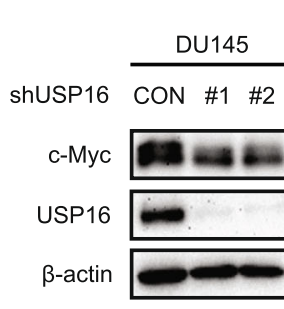

e

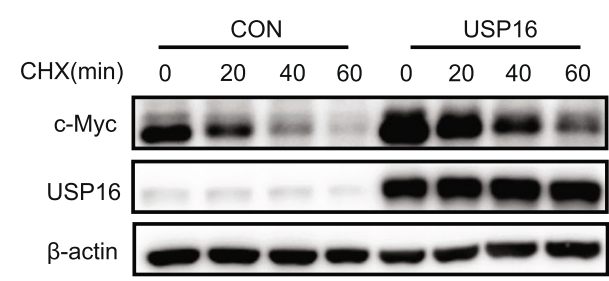

f

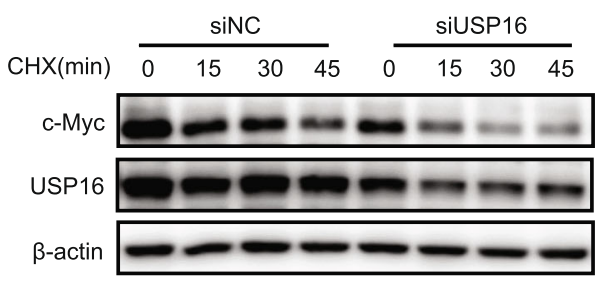

C

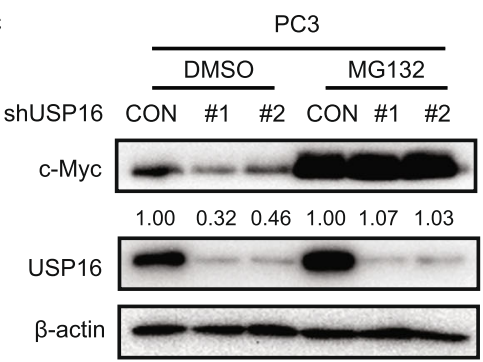

d
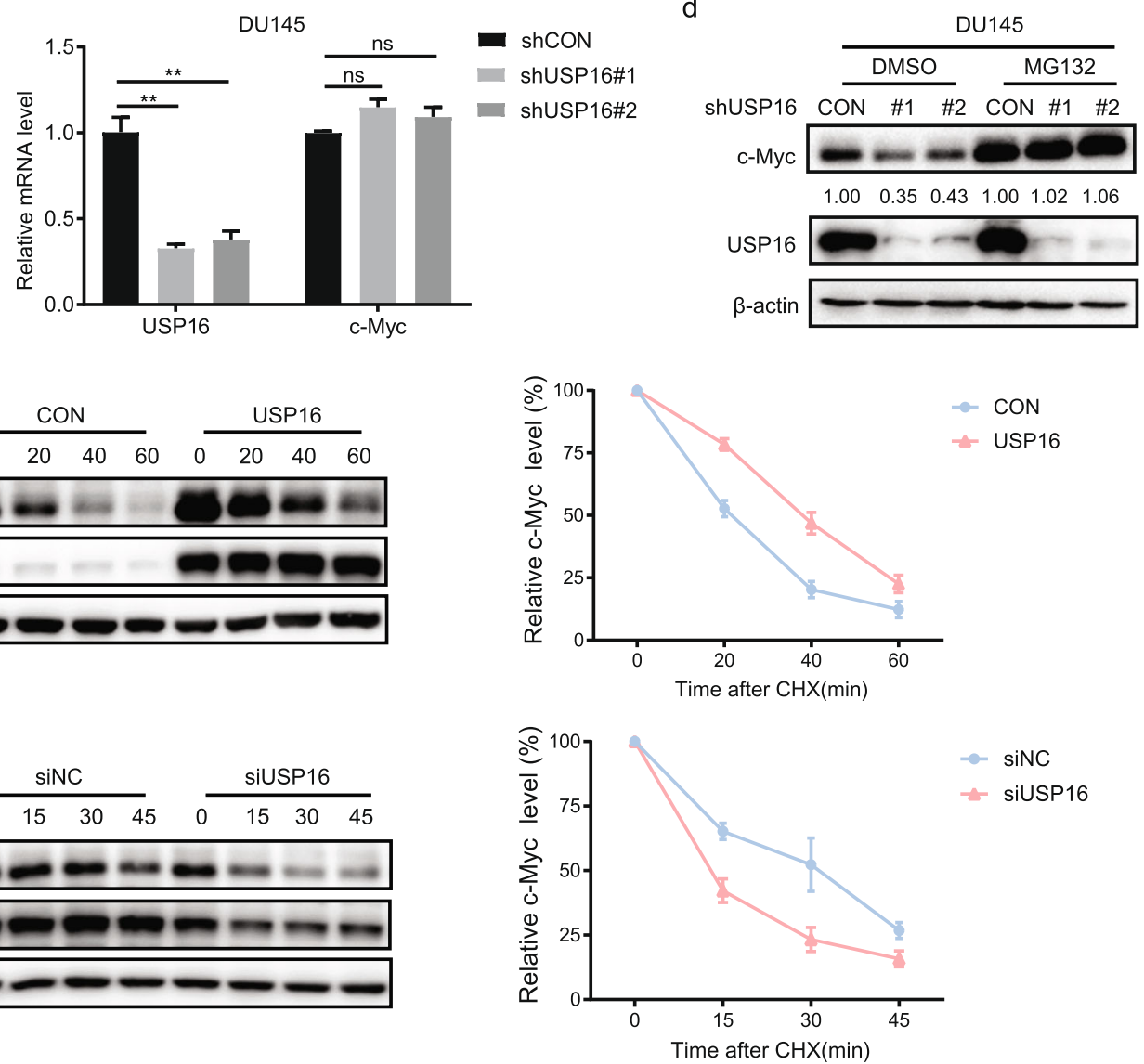

Fig. 4 USP16 regulates c-Myc stability at the post-transcriptional level. a and $\mathbf{b}$ Expression of USP16 and c-Myc proteins were measured by Western blot, and mRNA levels of USP16 and c-Myc were detected by qRT-PCR. $\mathbf{c}$ and $\mathbf{d}$ PC3 and DU145 cells were treated with $10 \mu \mathrm{mol} / \mathrm{L}$ of MG132 for $6 \mathrm{~h}$ and then lysed. e and $\mathbf{f}$ PC3 cells were transfected, treated with $50 \mathrm{\mu g} / \mathrm{ml}$ of CHX, and harvested at the indicated times. The plot illustrates c-Myc band intensities quantified by densitometry 


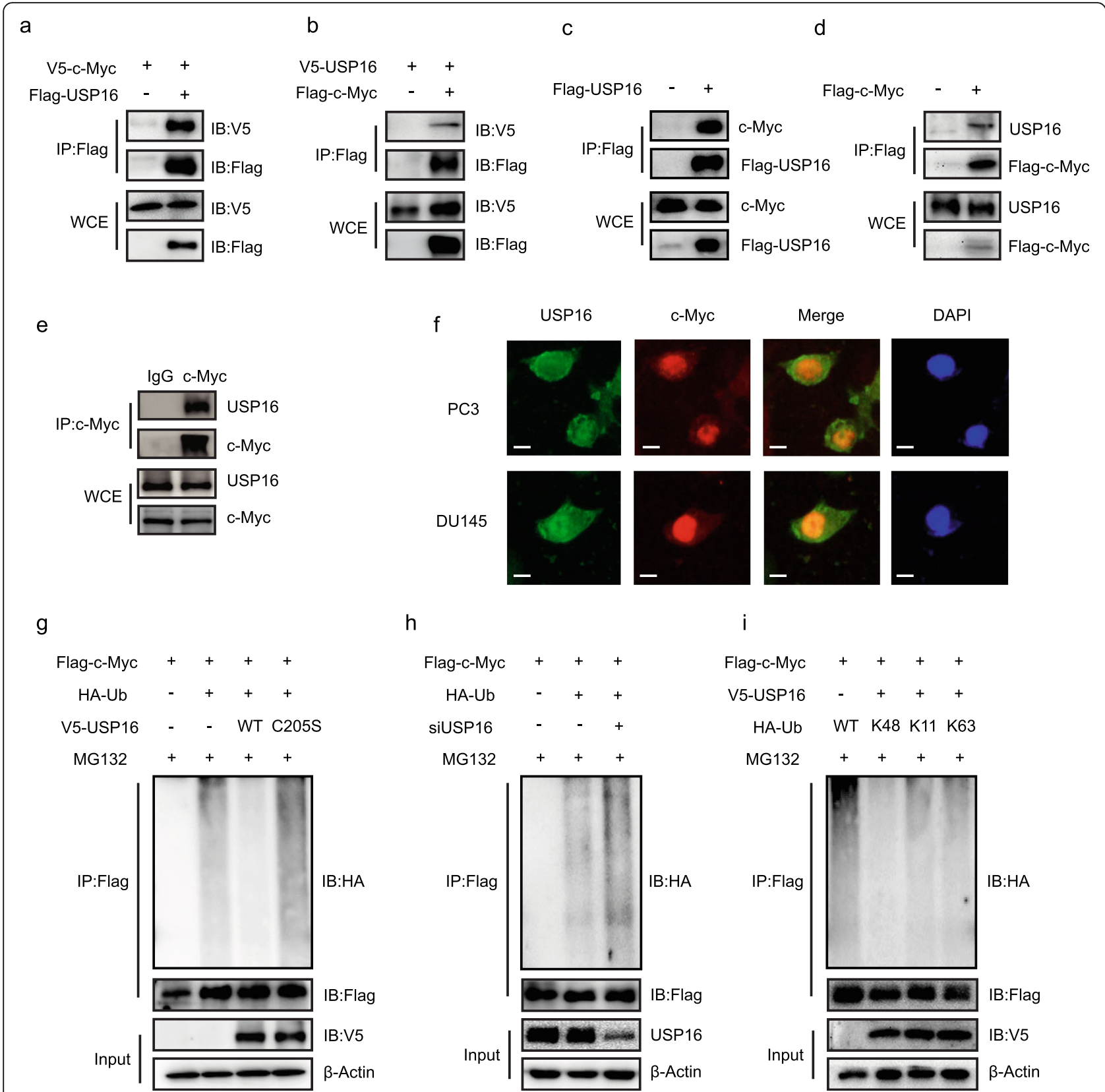

Fig. 5 USP16 co-localizes and interacts with c-Myc. a and $\mathbf{b}$ Indicated plasmids were transfected into HEK293T cells alone or in combination, and an anti-Flag antibody was used for immunoprecipitation. IP, immunoprecipitation; IB immunoblotting; WCE, whole-cell extract. $\mathbf{c}$ and $\mathbf{d}$ Exogenous USP16 or c-Myc was immunoprecipitated from PC3 cells using an anti-Flag antibody. Endogenous c-Myc or USP16 was analysed by Western blot. e Interaction between endogenous c-Myc and USP16 in PC3 cells was analysed by Western blot. $\mathbf{f}$ Immunofluorescent staining of USP16 and c-Myc in PC3 and DU145 cells. Scale bar, 10 mm. g Flag-c-Myc and HA-ubiquitin were co-transfected with v5-USP16 or v5-C205s, and the ubiquitination of c-Myc was measured using an in vivo ubiquitination assay. Precipitates and WCEs were analysed by Western blot. $\mathbf{h}$ Control siRNA (siNC) or siUSP16 was transfected into HEK293T cells. After $48 \mathrm{~h}$, cells were transduced with Flag-c-Myc and HA-Ub for $24 \mathrm{~h}$ and then harvested. i HEK293T cells were transfected with v5-USP16, Flag-c-Myc, and different forms of HA-ubiquitins. Cell lysates were immunoprecipitated with an anti-Flag antibody and ubiquitination levels were measured using an anti-HA antibody

HA-ubiquitin and Flag-c-Myc with wild-type USP16 or its catalytically inactive mutant USP16-C205S and treated with MG132. As shown in Fig. 5g, the wild-type USP16, but not USP16-C205S, markedly reduced the ubiquitination of c-Myc. Besides, the knockdown of
USP16 significantly enhanced the polyubiquitination of c-Myc (Fig. 5h).

Next, we identified which polyubiquitin modification of c-Myc protein was regulated by USP16. HEK293T cells were transfected with v5-USP16 and Flag-c-Myc, 


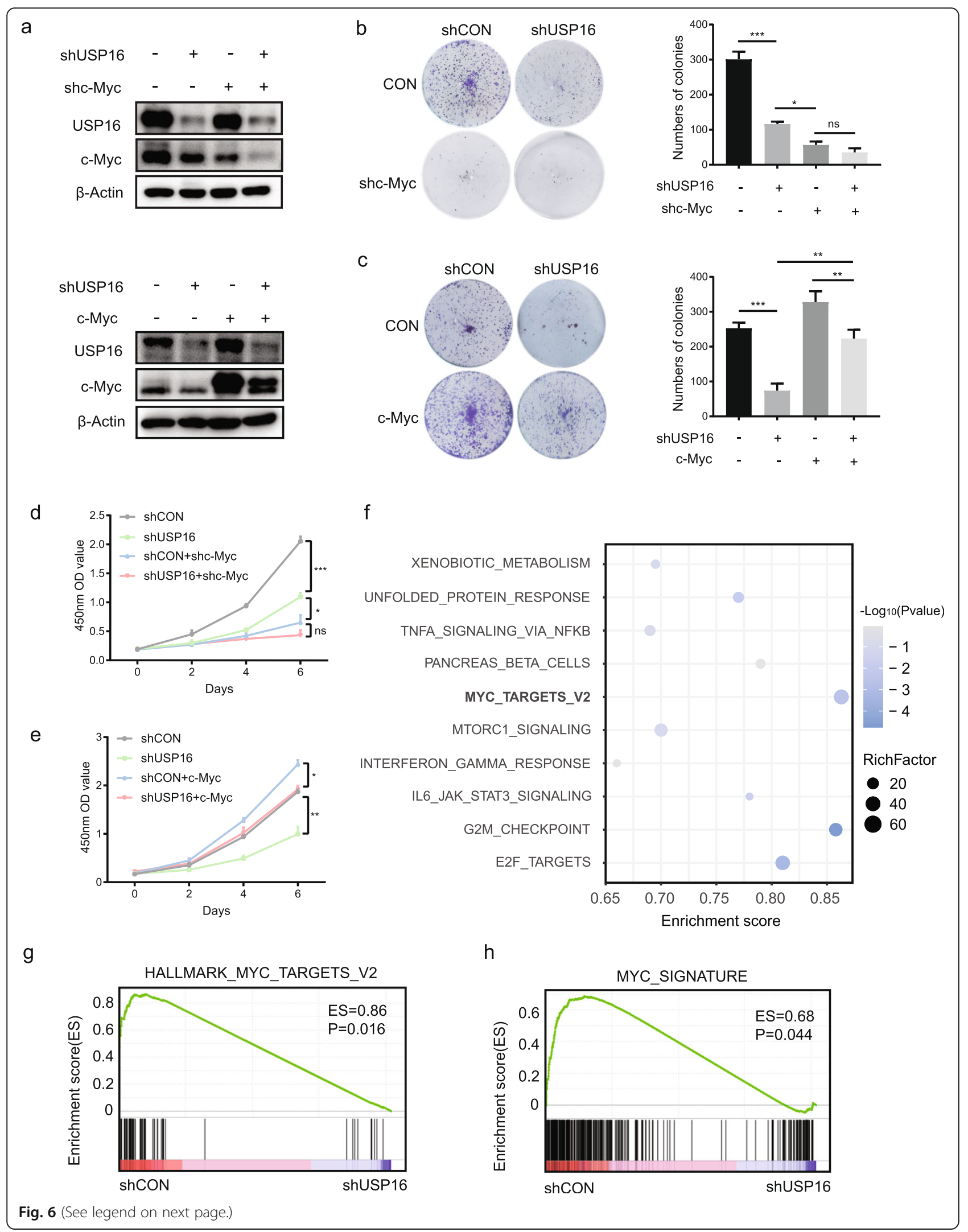


(See figure on previous page.)

Fig. 6 USP16 regulates PCa cell proliferation via c-Myc. a Expression of USP16 and c-Myc was evaluated by Western blot. b and c PC3 cells were transfected with the indicated plasmids and cell growth was measured by colony formation assay. $\mathbf{d}$ and $\mathbf{e}$ Cell viability was determined by CCK8 assay. $\mathbf{f}$ Bubble plot of GSEA results. $\mathbf{g}$ and $\mathbf{h}$ Gene expression profiles of PC3 cells with or without knockdown of USP16 based on the Myc target and signature gene set

along with one each of the different HA-ubiquitins (WT, K11, K48, or K63). Cell lysates were then immunoprecipitated with an anti-Flag antibody and subjected to immunoblotting analysis using an anti-HA antibody. The results revealed that the K48-linked ubiquitination of cMyc was substantially reduced by USP16 (Fig. 5i).

\section{USP16 regulates PCa cell growth through c-Myc}

$\mathrm{c}-\mathrm{Myc}$ is an oncoprotein involved in cell proliferation, and overexpression of c-Myc is known to enhance the viability of several cancer cells [24]. Given that USP16 regulates the stability of $\mathrm{c}-\mathrm{Myc}$, we examined whether USP16 regulates cell growth through c-Myc. We either disrupted or overexpressed c-Myc under conditions of USP16 knockdown. The protein levels of USP16 and cMyc were measured using Western blot (Fig. 6a). Colony formation assays results suggest that c-Myc knockdown could abolish the effect of USP16 knockdown in terms of both cell proliferation and growth (Fig. 6b). Moreover, c-Myc overexpression restored the proliferation and colony formation abilities of USP16 silenced cells (Fig. 6c). These findings were further confirmed by CCK- 8 assays (Fig. 6d and e).

We then performed RNA-Seq analysis of PC3 cells with or without USP16 knockdown and the gene expression profiles were analysed by GSEA (Fig. $6 \mathrm{f}$ ). Consistent with the previous screening results of published datasets, the Myc targets and Myc gene signature gene set were significantly enriched in the control group (Fig. $6 \mathrm{~g}$ and h). Together, these data indicate that USP16 regulates PCa cell proliferation mainly throughs stabilizing c-Myc.

\section{USP16 expression is elevated in prostate cancer}

Next, we sought to confirm our results in clinical samples. We characterized USP16 expression in PCa $(n=70)$ and adjacent normal tissues $(n=70)$ via IHC staining. The staining scores of normal prostate tissues were markedly weaker than PCa tissues (Fig. 7a). Furthermore, we noticed that the USP16 staining scores were significantly correlated with the Gleason scores ( $\chi^{2}$ test; $p<0.05$; Fig. $7 \mathrm{~b}$ and c), which indicates the essential role played by USP16 in PCa development.

To further assess the association between USP16 and $\mathrm{c}-\mathrm{Myc}$ in PCa, we detected the expression of USP16 and c-Myc using tissue microarrays containing 82 human PCa tissues. Consequently, a positive correlation was found between the staining scores of USP16 and c-Myc (Fig. 7d-f). Thus, these results revealed the clinical relevance of USP16-mediated regulation of c-Myc in PCa development.

\section{Discussion}

Deubiquitination is a widespread post-translational modification of proteins that affects diverse biological processes. DUBs can remove ubiquitin from substrates and thus stabilize target proteins, as well as regulate their subcellular localization and function [25]. Ubiquitin-specific proteases (USPs) account for the majority of DUBs and are involved in a variety of cellular processes including cell proliferation, differentiation, and metabolism [26]. Furthermore, USPs are significantly correlated with the occurrence of numerous cancers including PCa. For example, USP10 interacts with G3BP2 to block p53 signal transduction, leading to poor prognosis in prostate cancer [27]; USP44 promotes the development of prostate cancer by stabilizing EZH2 [28], and USP2a enhances c-Myc expression via microRNArelated regulation and thus promotes tumourigenesis [29]. Moreover, the AR protein, which is frequently dysregulated in $\mathrm{PCa}$, has been reported as a substrate for several USPs including USP12 [30], USP22 [31], USP26 [32], and USP7 [33]. Besides controlling AR and ARv7, USP7 is also in charge of the stability of the CCDC6 gene product, a tumor suppressor whose impairment induces a BRCAness-like phenotype which associates to PARP inhibitors sensitivity in prostate and urothelial cancer [34-36].

In $\mathrm{PCa}, \mathrm{c}-\mathrm{Myc}$ plays a key role in disease progression [16], and c-Myc expression is positively correlated with advanced histologic grade and poor prognosis. Hubbard et al. found that the combination of Myc activation and Pten loss could result in lethal prostate cancer [37]. However, despite this strong evidence linking c-Myc and disease pathology, few effective treatments have targeted c-Myc due to its structure and location [38]. As a transcription factor, c-Myc lacks enzymatic activity, making it difficult to target by small molecules. Additionally, cMyc is predominantly located in the nucleus, thereby rendering monoclonal antibody-based therapies impractical [39]. To overcome this limitation, researchers have instead focused on targets upstream of c-Myc, such as BET bromodomain inhibitors [40], which have demonstrated preclinical efficacy in models of c-Myc-driven CRPC and shown considerable promise as a therapy for PCa [41]. 
a

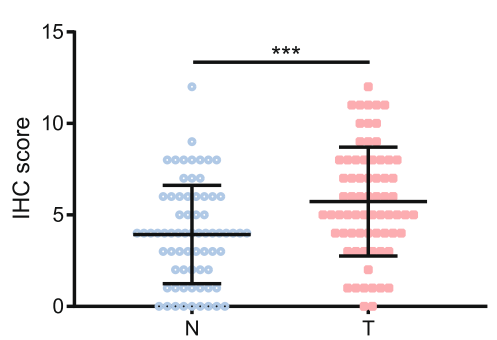

C

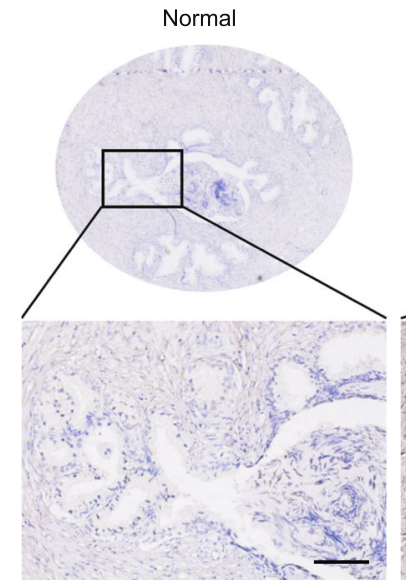

low GS
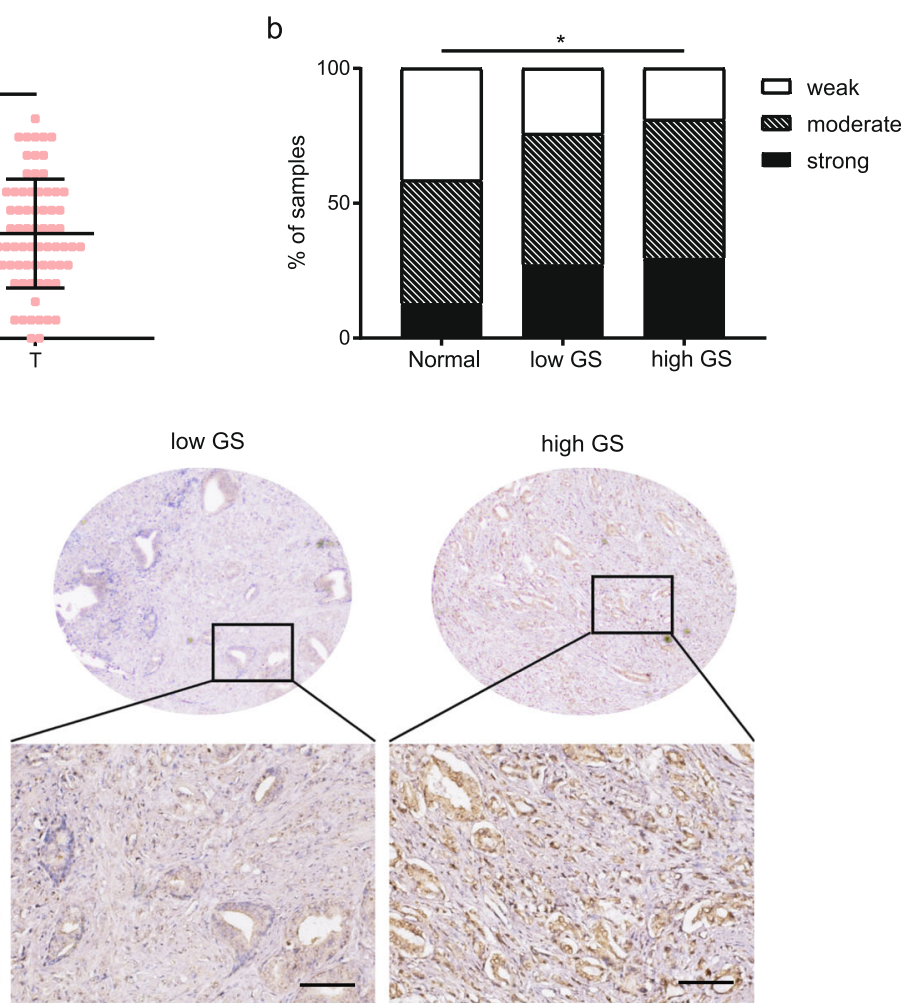

d

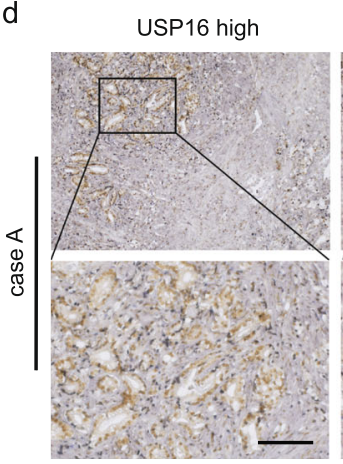

c-Myc high

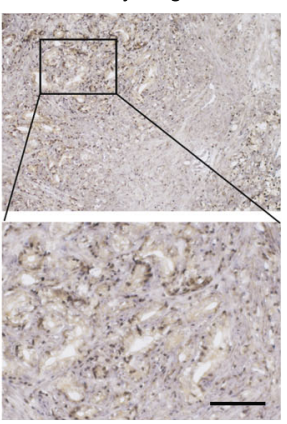

c-Myc low

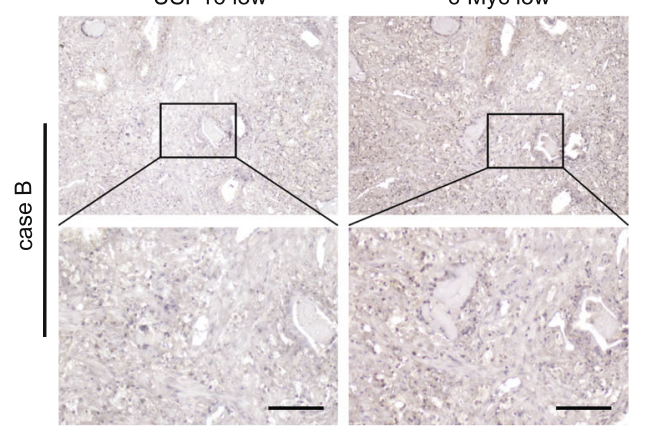

e

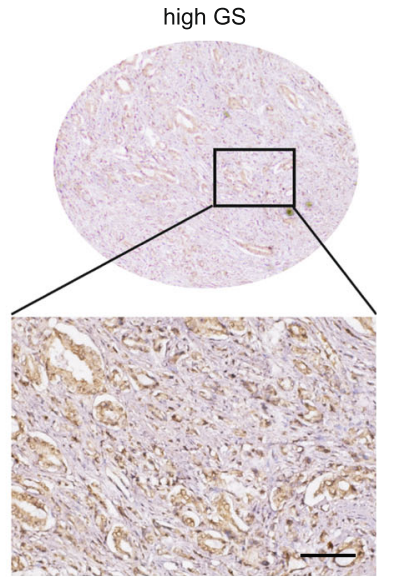

f

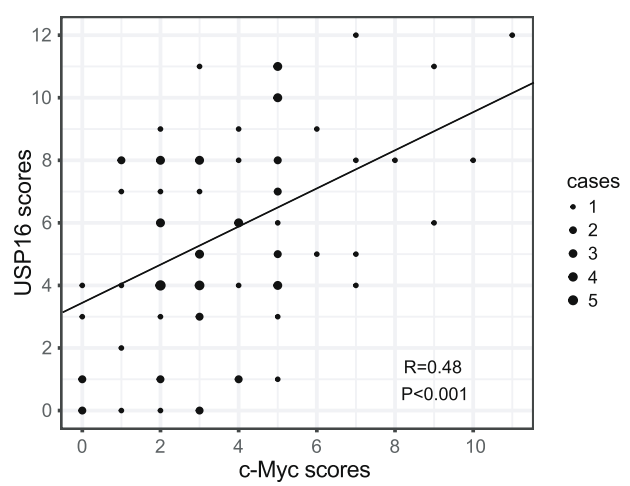

Fig. 7 (See legend on next page.) 
(See figure on previous page.)

Fig. 7 USP16 expression is upregulated in prostate cancer. a Expression of POH1 in normal prostate tissues (N) and PCa tissues (T) were examined by IHC (Mann-Whitney test, $p<0.001$ ). b Distribution of USP16 expression among prostate samples as indicated ( $\mathrm{N}$, normal prostate; low GS, Gleason scores $\leq 3+4$; high GS, Gleason scores $\geq 4+3$; weak, IHC scores $\leq 4$; mod, $4<\mathrm{IHC}$ scores $\leq 8$; strong, $1 \mathrm{HC}$ scores $>8)(x 2$ test; $p<$ 0.05). c Representative images of prostate samples (scale bar: $100 \mu \mathrm{m})$. d Case A: a representative sample with high USP16 and c-Myc staining. Case B: a representative sample with low USP16 and c-Myc staining. Scale bar: $100 \mu \mathrm{m}$. e Quantification of the staining revealed a statistically significant correlation. ( $X 2$ test; $p<0.01$ ); $\mathbf{f}$ Correlation between USP16 and c-Myc expression in PCa samples are shown (Spearman correlation test; $p<0.001)$. $\mathrm{R}$ indicates the correlation coefficient

Given the strong transcription-promoting activity of cMyc, it is not surprising that c-Myc abundance is tightly controlled by multiple mechanisms [42]. One of the most significant mechanisms maintaining appropriate cMyc protein levels is the ubiquitin-proteasome system (UPS). In the present study, we found that the targeted disruption of USP16, but not other deubiquitinases of cMyc, reduced c-Myc protein levels in $\mathrm{PCa}$, indicating that DUBs have different functions in different cancers.

It has been reported that USP16, one of the deubiquitinases of Histone $\mathrm{H} 2 \mathrm{~A}$, is required for removing ubH2A-mediated repression during the differentiation of embryonic stem cells [23]. Besides, USP16 can regulate hematopoiesis and the function of hematopoietic stem cells [43] . However, the role of USP16 in tumourigenesis remains poorly understood. Here, we demonstrated that USP16 knockdown notably impaired PCa cell proliferation both in vitro and in vivo. In addition, we found USP16 regulates PCa cell growth through stabilizing cMyc. Furthermore, USP16 expression was upregulated in $\mathrm{PCa}$ tissues and correlated with $\mathrm{PCa}$ pathological grade and c-Myc expression, suggesting that USP16 plays a critical role in PCa tumourigenesis and could be a therapeutic target of PCa.

As indicated in Fig. 6f, USP16 knockdown may result in potential effects independent from c-Myc, such as G2M checkpoint and E2F targets. It has been reported that the silence of USP16 in Hela cells could decrease the proportion of cells at $\mathrm{G} 2 / \mathrm{M}$ partially due to the defects of $\mathrm{H} 2 \mathrm{~A}$ deubiquitination during G2/M phase progression [44]. In addition, HSCARG, a negative regulator of H2A ubiquitination, is necessary for cell proliferation and the deletion of HSCARG could activate checkpoint signaling and impair cell viability [45]. Besides, USP21 could promote transcription by deubiquitylating ubH2A in vitro [46]. Therefore, the deubiquitination of $\mathrm{H} 2 \mathrm{~A}$ by USP16 may also play a role in prostate cancer cell proliferation to some extent, which remains further investigated. On the other hand, c-Myc target genes include critical positive cell cycle regulators like cyclindependent kinases, cyclins and E2F transcription factors [47]. Moreover, c-Myc promoter contains an E2F binding site which is crucial for c-Myc expression [48]. In brief, c-Myc has synergistic effect with E2F and the specific mechanism between c-Myc and E2F awaits further study. Additional work will be required to determine which part of c-Myc transcriptional network could be regulated by USP16 so that we could find the key genes or pathways involving transformation of CRPC or NEPC. Besides, it remains to explore whether $\mathrm{c}-\mathrm{Myc}$ signalling could activate USP16 expression, resulting in a positive feedback loop that further promotes tumourigenesis.

\section{Conclusion}

Our study identified USP16 as a novel deubiquitinase of cMyc and revealed its important role in the development and progress of PCa. RNA-seq data from PCa cells demonstrated that USP16 was strongly associated with c-Myc expression signatures and downstream targets. And the positive correlation between USP16 and c-Myc was further confirmed by IHC staining of tissue microarray. Given the essential role played by c-Myc in PCa, targeting USP16 may represent a potential therapy for PCa treatment.

\section{Supplementary Information}

The online version contains supplementary material available at https://doi. org/10.1186/s13046-021-01843-8.

Additional file 1: Table S1. qPCR primers and shRNAs sequences.

Additional file 2: Table S2. c-Myc gene signature.

Additional file 3: Fig. S1. Films of long and short exposure in cycloheximide chase assay.

\section{Abbreviations}

AR: Androgen receptor; CCK8: Cell counting kit-8; CHX: Cycloheximide; CRPC: Castration-resistant prostate cancer; DUB: Deubiquitinase; GS: Gleason scores; GSEA: Gene set enrichment analysis; IHC: Immunohistochemistry; IP: Immunoprecipitation; PCa: Prostate cancer; qRT-PCR: Quantitative realtime polymerase chain reaction; UPS: Ubiquitin proteasome system; USP16: Ubiquitin-specific protease 16; USPS: Ubiquitin-specific proteases; WCE: Whole-cell extract

\section{Acknowledgments}

Not applicable.

\section{Authors' contributions}

SGW designed the study; GJC, YWD and LJH performed the experiments; GJC, MHB, WPY and ZYH analysed the data; GJC and YWD wrote the manuscript. SGW, ZJ and WY reviewed the manuscript. All authors read and approved the final manuscript.

\section{Funding}

This study was funded by Shanghai Fifth People's Hospital, Fudan University (Grant No. 2018WYZD02), Natural Science Foundation of Shanghai (Grant No. 18ZR1429800) and the Shanghai Key Medical Specialty Program (Grant No. ZK2019A03). 


\section{Availability of data and materials}

The datasets supporting the findings of this study are indicated in the article.

\section{Ethics approval and consent to participate}

All animal procedures were approved by the Institutional Animal Care and Use Committee of Shanghai Veterinary Research Institute.

\section{Consent for publication}

All authors have agreed to publish this manuscript.

\section{Competing interests}

The authors declare that there are no competing interests.

Received: 18 November 2020 Accepted: 13 January 2021

Published online: 05 February 2021

\section{References}

1. Siegel RL, Miller KD, Jemal A. Cancer statistics, 2018. CA Cancer J Clin. 2018; 68(1):7-30.

2. Shafi AA, Yen AE, Weigel NL. Androgen receptors in hormone-dependent and castration-resistant prostate cancer. Pharmacol Ther. 2013;140(3):223-38.

3. Heinlein CA, Chang C. Androgen receptor in prostate cancer. Endocr Rev. 2004;25(2):276-308.

4. Attard G, Parker C, Eeles RA, Schröder F, Tomlins SA, Tannock I, et al. Prostate cancer. Lancet. 2016:387(10013):70-82.

5. Petrylak DP, Tangen CM, Hussain MH, et al. Docetaxel and estramustine compared with mitoxantrone and prednisone for advanced refractory prostate cancer. N Engl J Med. 2004;351:1513-20.

6. Dang CV, O'Donnell KA, Zeller KI, Nguyen T, Osthus RC, Li F. The c-Myc target gene network. Semin Cancer Biol. 2006;16(4):253-64

7. Gordan JD, Bertout JA, Hu CJ, Diehl JA, Simon MC. HIF-2alpha promotes hypoxic cell proliferation by enhancing c-myc transcriptional activity. Cancer Cell. 2007;11(4):335-47.

8. Hung $C L$, Wang $L Y, Y u Y L$, Chen HW, Srivastava S, Petrovics $G$, et al. A long noncoding RNA connects C-Myc to tumor metabolism. Proc Natl Acad Sci U S A. 2014;111(52):18697-702.

9. Lin CJ, Cencic R, Mills JR, Robert F, Pelletier J. C-Myc and elF4F are components of a feedforward loop that links transcription and translation. Cancer Res. 2008;68(13):5326-34.

10. Morrish F, Isern N, Sadilek M, Jeffrey M, Hockenbery DM. C-Myc activates multiple metabolic networks to generate substrates for cell-cycle entry. Oncogene. 2009;28(27):2485-91.

11. Dardenne E, Beltran H, Benelli M, Gayvert K, Berger A, Puca L, et al. N-Myc induces an $\mathrm{EZH} 2$-mediated transcriptional program driving neuroendocrine prostate Cancer. Cancer Cell. 2016;30(4):563-77.

12. Pettersson A, Gerke T, Penney KL, Lis RT, Stack EC, Pertega-Gomes N, et al. MYC overexpression at the protein and mRNA level and Cancer outcomes among men treated with radical prostatectomy for prostate Cancer. Cancer Epidemiol Biomark Prev. 2018;27(2):201-7.

13. Lee JK, Phillips JW, Smith BA, Park JW, Stoyanova T, McCaffrey EF, et al. NMyc drives neuroendocrine prostate Cancer initiated from human prostate epithelial cells. Cancer Cell. 2016;29(4):536-47.

14. Hofmann JW, Zhao X, De Cecco M, Peterson AL, Pagliaroli L, Manivannan J, et al. Reduced expression of MYC increases longevity and enhances healthspan. Cell. 2015;160(3):477-88.

15. Komander D, Rape M. The ubiquitin code. Annu Rev Biochem. 2012;81: 203-29.

16. Mevissen TET, Komander D. Mechanisms of Deubiquitinase specificity and regulation. Annu Rev Biochem. 2017:86:159-92.

17. Farrell AS, Sears RC. MYC degradation. Cold Spring Harb Perspect Med. 2014;4(3):a014365-a014365.

18. Tavana O, Li D, Dai C, Lopez G, Banerjee D, Kon N, et al. HAUSP deubiquitinates and stabilizes N-Myc in neuroblastoma. Nat Med. 2016; 22(10):1180-6.

19. Kim D, Hong A, Park HI, Shin WH, Yoo L, Jeon SJ, et al. Deubiquitinating enzyme USP22 positively regulates C-Myc stability and tumorigenic activity in mammalian and breast cancer cells. J Cell Physiol. 2017;232(12):3664-76.

20. Popov N, Wanzel M, Madiredjo M, Zhang D, Beijersbergen R, Bernards R, et al. The ubiquitin-specific protease USP28 is required for MYC stability. Nat Cell Biol. 2007;9(7):765-74.
21. Sun XX, He X, Yin L, Komada M, Sears RC, Dai MS. The nucleolar ubiquitinspecific protease USP36 deubiquitinates and stabilizes c-Myc. Proc Natl Acad Sci U S A. 2015;112(12):3734-9.

22. Pan J, Deng Q, Jiang C, Wang X, Niu T, Li H, et al. USP37 directly deubiquitinates and stabilizes C-Myc in lung cancer. Oncogene. 2015;34(30):3957-67.

23. Yang W, Lee $Y-H$, Jones AE, Woolnough JL, Zhou D, Dai Q, et al. The histone $\mathrm{H} 2 \mathrm{~A}$ deubiquitinase Usp16 regulates embryonic stem cell gene expression and lineage commitment. Nat Commun. 2014;5(1):3818.

24. Dang CV. MYC on the path to cancer. Cell. 2012;149(1):22-35.

25. Komander D, Clague MJ, Urbe S. Breaking the chains: structure and function of the deubiquitinases. Nat Rev Mol Cell Biol. 2009;10(8):550-63.

26. Islam MT, Zhou X, Chen F, Khan MA, Fu J, Chen H. Targeting the signalling pathways regulated by deubiquitinases for prostate cancer therapeutics. Cell Biochem Funct. 2019;37(5):304-19.

27. Takayama Kl, Suzuki T, Fujimura T, Takahashi S, Inoue S. Association of USP10 with G3BP2 inhibits p53 signaling and contributes to poor outcome in prostate Cancer. Mol Cancer Res. 2018;16(5):846-56.

28. Park JM, Lee JE, Park CM, Kim JH. USP44 promotes the tumorigenesis of prostate Cancer cells through EZH2 protein stabilization. Mol Cells. 2019; 42(1):17-27

29. Benassi B, Flavin R, Marchionni L, Zanata S, Pan Y, Chowdhury D, et al. MYC is activated by USP2a-mediated modulation of microRNAs in prostate cancer. Cancer Discov. 2012;2(3):236-47.

30. Burska UL, Harle VJ, Coffey K, Darby S, Ramsey H, O'Neill D, et al. Deubiquitinating enzyme Usp12 is a novel co-activator of the androgen receptor. J Biol Chem. 2013;288(45):32641-50.

31. Schrecengost RS, Dean JL, Goodwin JF, Schiewer MJ, Urban MW, Stanek TJ, et al. USP22 regulates oncogenic signaling pathways to drive lethal cancer progression. Cancer Res. 2014;74(1):272-86.

32. Dirac AM, Bernards R. The deubiquitinating enzyme USP26 is a regulator of androgen receptor signaling. Mol Cancer Res. 2010;8(6):844-54.

33. Chen ST, Okada M, Nakato R, Izumi K, Bando M, Shirahige K. The Deubiquitinating enzyme USP7 regulates androgen receptor activity by modulating its binding to chromatin. J Biol Chem. 2015;290(35):21713-23.

34. Leone V, Langella C, Esposito F, Arra C, Fusco A. Ccdc6 knock-in mice develop thyroid hyperplasia associated to an enhanced CREB1 activity. Oncotarget. 2015;6(17):15628-38.

35. Morra F, Merolla F, Criscuolo D, Insabato L, Giannella R, llardi G, et al. CCDC6 and USP7 expression levels suggest novel treatment options in high-grade urothelial bladder cancer. J Exp Clin Cancer Res. 2019;38(1):90.

36. Criscuolo D, Morra F, Giannella R, Cerrato A, Celetti A. Identification of novel biomarkers of homologous recombination defect in DNA repair to predict sensitivity of prostate cancer cells to PARP-inhibitors. Int J Mol Sci. 2019; 20(12):3100.

37. Hubbard GK, Mutton LN, Khalili M, McMullin RP, Hicks JL, Bianchi-Frias D, et al. Combined MYC activation and Pten loss are sufficient to create genomic instability and lethal metastatic prostate Cancer. Cancer Res. 2016; 76(2):283-92.

38. McKeown MR, Bradner JE. Therapeutic strategies to inhibit MYC. Cold Spring Harb Perspect Med. 2014;4(10):a014266.

39. Chen H, Liu H, Qing G. Targeting oncogenic Myc as a strategy for cancer treatment. Signal Transduct Target Ther. 2018;3:5.

40. Asangani IA, Dommeti VL, Wang X, Malik R, Cieslik M, Yang R, et al. Therapeutic targeting of BET bromodomain proteins in castration-resistant prostate cancer. Nature. 2014:510(7504):278-82.

41. Faivre EJ, McDaniel KF, Albert DH, Mantena SR, Plotnik JP, Wilcox D, et al. Selective inhibition of the BD2 bromodomain of BET proteins in prostate cancer. Nature. 2020;578(7794):306-10.

42. Thomas LR, Tansey WP. Proteolytic control of the oncoprotein transcription factor Myc. Adv Cancer Res. 2011;110:77-106.

43. Gu Y, Jones AE, Yang W, Liu S, Wang $H$. The histone H2A deubiquitinase Usp16 regulates hematopoiesis and hematopoietic stem cell function. Proc Natl Acad Sci U S A. 2016;113(1):E51.

44. Joo HY, Zhai L, Yang C, Nie S, Erdjument-Bromage H, Tempst $\mathrm{P}$, et al. Regulation of cell cycle progression and gene expression by $\mathrm{H} 2 \mathrm{~A}$ deubiquitination. Nature. 2007:449(7165):1068-72.

45. Hu B, Li S, Zhang $X$, Zheng X. HSCARG, a novel regulator of $\mathrm{H}_{2} \mathrm{~A}$ ubiquitination by downregulating PRC1 ubiquitin E3 ligase activity, is essential for cell proliferation. Nucleic Acids Res. 2014;42(9):5582-93.

46. Okuda H, Ohdan H, Nakayama M, Koseki H, Nakagawa T, Ito T. The USP21 short variant (USP21SV) lacking NES, located mostly in the nucleus in vivo, 
activates transcription by deubiquitylating ubH2A in vitro. PLoS One. 2013; 8(11):e79813.

47. Bretones G, Delgado MD, Leon J. Myc and cell cycle control. Biochim Biophys Acta. 2015;1849(5):506-16.

48. Oswald F, Lovec H, Möröy T, Lipp M. E2F-dependent regulation of human MYC: trans-activation by cyclins D1 and a overrides tumour suppressor protein functions. Oncogene. 1994;9(7):2029-36.

\section{Publisher's Note}

Springer Nature remains neutral with regard to jurisdictional claims in published maps and institutional affiliations.

Ready to submit your research? Choose BMC and benefit from:

- fast, convenient online submission

- thorough peer review by experienced researchers in your field

- rapid publication on acceptance

- support for research data, including large and complex data types

- gold Open Access which fosters wider collaboration and increased citations

- maximum visibility for your research: over $100 \mathrm{M}$ website views per year

At $\mathrm{BMC}$, research is always in progress. 